\begin{tabular}{|c|c|c|}
\hline $\begin{array}{l}\text { PKS } \\
\text { PUBDLC }\end{array}$ & $\begin{array}{l}\text { REVISTA DE GEOGRAFIA } \\
\text { (RECIFE) }\end{array}$ & $\begin{array}{l}\text { OJS } \\
\text { OPEN } \\
\text { JOUNAL }\end{array}$ \\
\hline & revista.u & \\
\hline
\end{tabular}

\title{
COMPARTIMENTAÇÃO GEOMORFOLÓGICA DA PLANÍCIE DO RECIFE, PERNAMBUCO, BRASIL
}

\author{
Joazadaque Lucena de Souza ${ }^{1}$; Antonio Carlos de Barros Corrêa ${ }^{2}$; Osvaldo Girão da Silva ${ }^{3}$ \\ ${ }^{1}$ Mestre em Geografia pela Universidade Federal de Pernambuco; Email: joazadaque@hotmail.com \\ ${ }^{2}$ Professor Adjunto do Programa de Pós-Graduação em Geografia da Universidade Federal de Pernambuco; \\ Email:dbiase2001@terra.com.br \\ ${ }_{3}^{3}$ Professor Adjunto do Programa de Pós-Graduação em Geografia da Universidade Federal de Pernambuco; \\ Email: osgirao@gmail.com
}

Artigo recebido em 08/01/2017 e aceito em 15/03/2017

\begin{abstract}
RESUMO
O seguinte estudo propõe uma compartimentação geomorfológica da planície do Recife, Pernambuco, Brasil a partir da criação de uma tipologia de unidades de relevo com o objetivo de estabelecer recortes espaciais capazes de serem utilizados para subsidiar o planejamento do uso da terra da área de estudo. Esse sistema classificação baseia-se na identificação dos depósitos quaternários; análise da gênese e evolução das formas de relevo; verificação da atuação de processos de superfície; alterações promovidas pela ação antrópica nos diferentes setores da planície. Para alcançar os objetivos foi elaborada uma tipologia de unidades de relevo com duas ordens de grandeza distintas; análise dos ambientes de sedimentação vigentes em cada uma das porções do ambiente de planície; e a confecção de mapas temáticos em escala de 1:100.000 com o uso Software ArcGis 9.3 com o intuito de representar espacialmente as morfologias. Na primeira ordem de grandeza temos as Unidades Geoambientais: I- Corpos hídricos e canais fluviais, II- Planície fluvial, III- Planície fluviomarinha, IV- Planície indiferenciada e V- Planície marinha. O segundo nível hierárquico compõe as Unidades de Relevo: 1- Terraço marinho holocênico, 2- Terraço marinho pleistocênico, 3- Terraço fluviomarinho holocênico, 4- Terraço indiferenciado, 5- Planície de maré, 6- Planície fluviolagunar, 7- Planície de Restinga, 8- Planície Colúvioaluvial Indiferenciada e 9- Corpos hídricos e canais fluviais.

Palavras-chave: compartimentação; tipologia; unidades de relevo; planície do Recife; uso da terra.
\end{abstract}

\section{GEOMORPHOLOGICAL COMPARTIMENTATION OF THE PLAIN OF RECIFE, STATE OF PERNAMBUCO, BRAZIL}

\begin{abstract}
The following study proposes a geomorphological compartmentalization of the Recife plain, state of Pernambuco, based on the creation of a typology of landforms with the objective of establishing spatial cuttings capable of being used to subsidize land use planning in the area of study. This classification system is based on the identification of quaternary deposits; analysis of the genesis and evolution of landforms; verification of the performance of surface processes and changes made by anthropic action in the different sectors of the plain; Creation of a typology of landforms with two different orders of magnitude and the making of thematic maps in a scale of 1: 100,000 with the use of ArcGis 9.3 Software to spatially represent two distinct hierarchical scales. The first, the Geoenvironmental Units composed by:I- Water bodies and fluvial channels, II- Fluvial plain, IIIFluvial-marine plain, IV- Undifferentiated Plain and V- Marine Plain; and the second refers to the landforms, such as: 1- Holocene marine terrace, 2- Pleistocene marine terrace, 3- Holocene marine fluvial terrace, 4Undifferentiated terrace 5- Tidal plain, 6- Fluvial-lagoon plain, 7- Restinga Plain, 8-Undifferentiated alluvial colluvium plain and 9- Water bodies and fluvial channels.
\end{abstract}

Keywords: compartmentation; typology; landforms; Recife plain; land use. 


\section{INTRODUÇÃO}

A planície do Recife é uma área com características genéticas, morfológicas e processuais bastante complexas e por conta desse fato existem algumas dificuldades técnicas durante a elaboração de projetos ligados ao meio ambiente, infraestrutura e saneamento. Em decorrência desse fato surgem uma série de situações de risco geomorfológico relacionados ao escoamento superficial, transporte de sedimentos e erosão costeira em seus diversos setores, evidenciando a necessidade do desenvolvimento de estudos que consigam integrar os diversos elementos integrantes da paisagem de forma sistêmica para auxiliar no diagnóstico ambiental e na execução do planejamento urbano.

Tricart (1977) ao discorrer sobre o conceito de sistema afirma que o mesmo é o melhor instrumento lógico de que dispomos para estudar os problemas relacionados ao meio ambiente, permitindo adotar uma atitude dialética entre a necessidade da análise, aliada a uma visão de conjunto, capaz de ensejar uma atuação eficaz sobre as diferentes unidades de paisagem. Christofoletti (1979) afirma que a visão sistêmica concebe o mundo como um todo integrado, e não como uma coleção de partes dissociadas. Procurando compreender o conjunto mais que suas partes, pois há o surgimento de novas propriedades que não emergem do conhecimento de suas partes constituintes.

Evaso (1999) discorre que a paisagem é também a forma espacial do presente, porém testemunho de formas passadas que ainda persistem ou não. Revelando, assim, um dinamismo diacrônico, confirmando a evolução estrutural do processo espacial, demonstrando fases que poderão ser de estabilidade, de reformulação parcial ou de completa remodelação, engendrando novos espaços. Ross (2003) discorre que as formas de relevo se manifestam de modo diferenciado ao longo da superfície, em função das organizações de seus elementos e das interferências múltiplas dos demais componentes do estrato geográfico, traduzidas pela troca de energia e matéria entre os componentes numa dinâmica responsável pela gênese e evolução do modelado terrestre. O entendimento do relevo passa, portanto, por uma instância maior, denominada de Paisagem, não sendo possível entender a gênese e a dinâmica das formas de relevo sem que se entendam os mecanismos motores de sua geração e o funcionamento da dinâmica da estrutura superficial da paisagem.

Estudos de Souza (2013) reafirmam que a planície do Recife apresenta uma estrutura geológico-geomorfológica bastante complexa, em decorrência dos seus processos de formação e evolução estarem relacionados à vigência de condicionantes tectônicos e 
sedimentares ocorridos em diferentes escalas temporais, somadas a um intenso processo de ocupação urbana ocorrido nas últimas décadas. Como consequência, é dotada de características heterogêneas ao longo de sua extensão, o que possibilita a sua compartimentação em diversas unidades de paisagem. Este estudo se propõem a classificar seus ambientes em duas escalas hierárquicas distintas passíveis de serem delimitadas territorialmente e mapeadas com o uso de ferramentas de cartografia digital e geoprocessamento, evidenciando a importância da elaboração de material cartográfico para a representação, análise e compreensão dos fenômenos geográficos ocorridos na paisagem.

Segundo Girão e Corrêa (2004) a ação do homem constitui-se em um relevante agente modificador do meio ambiente, alterando o equilíbrio e a dinâmica dos processos naturais. Guerra e Marçal (2010) consideram que as paisagens também podem ser classificadas de acordo com o grau de intervenção antrópica, refletindo a complexidade de interação entre os componentes do ambiente, tornando difícil sua visualização de forma cartográfica, gerando grandes desafios à análise metodológica da paisagem de forma integrada. Pontuações feitas por Souza (2013) mostram que o elevado grau de alteração encontrado em cada uma das unidades de relevo da planície do Recife acaba gerando diversas modalidades de risco geomorfológico nas áreas compreendidas pela mesma. Essas mudanças ambientais são cíclicas, e por isso a resposta (output) do sistema a essas perturbações (input) contribuem para restabelecimento de novas condições de repouso, gerando novos processos geomorfológicos e a geração de formas de relevo com um maior grau de subordinação as condições ambientais vigentes, confirmando, assim, a relação muito próxima entre a mudança ambiental, a perda do equilíbrio, a geração de risco, o reajuste do sistema e as novas condições de equilíbrio do mesmo.

\section{MATERIAL E MÉTODOS}

\section{Fundamentação Teórica}

A análise de sistemas em geografia, assim como a sua vertente espacial, o Geossistema é a corrente filosófica e o arcabouço teórico-metodológico que melhor se adequa aos objetivos e resultados pretendidos com a presente pesquisa. No entender de Tricart (1977) um sistema é um conjunto de fenômenos que se processam mediante fluxos de matéria e energia, originando relações de dependência mútua entre os fenômenos. Como consequência, o sistema apresenta propriedades específicas que diferem da soma da soma das propriedades dos seus componentes. Não há um limite inferior para a descoberta de novos subsistemas: os 
estudos sobre os componentes da matéria sempre descobrem novas partículas cada vez menores. O limite superior é o universo. Dessa forma, o conceito lógico de sistema é a aplicação universal. As relações mútuas entre os subsistemas definem uma certa taxonomia a partir de uma escala hierárquica estabelecida entre os mesmos.

Beroutchvili e Bertrand (1978) avaliam que o Geossistema é um constructo teórico visto como unidade dimensional ideal que abarcaria a integridade da realidade concreta. Esta entidade, unidade de paisagem, é reconhecida como resultado da conjunção de fatores distintos, como a história geológica, a morfogênese do relevo, o clima em seu movimento, a dinâmica biológica e a participação da ação humana em sua evolução histórica. Christofoletti (1980) assegura que a aplicação da teoria geral dos sistemas aos estudos ambientais é capaz de analisar o funcionamento de um dado fenômeno como um todo integrado, concebendo-o como um sistema, composto de partes que somadas não conseguem reconstituir o nível de grandeza do todo, tendo em vista que a interação entre as partes é mais importante que a soma dos elementos integrantes, na formação da totalidade.

De acordo com Christofoletti (2000) os Geossistemas são sistemas ambientais físicos que se apresentam como unidades que possuem expressão concreta na superfície terrestre, sensível à observação visual através de imageamento remoto. Nesse sentido, só adquirem significância espacial e, por conseguinte, geográfica, quando da ocorrência de fenômenos naturais ou humanos ao longo do espaço. Corrêa (2006) mostra que o conceito de Geossistema permite à geografia avaliar a organização espacial levando em conta os componentes do quadro natural e sua funcionalidade. Um sistema em estado de equilíbrio é aquele em que os fluxos de energia e matéria são contínuos e, muitas vezes, cíclicos com o intuito da manutenção de sua dinâmica.

De acordo com Ross (2003) as formas de relevo não ocorrem de modo aleatório e caótico no espaço, sua ocorrência é derivada de uma série de fluxos de energia e matéria capazes de modificar a dinâmica do modelado das camadas superficiais de nosso planeta. Elas estão intimamente ligadas às características tectônicas, sedimentológicas, estratigráficas, pedológicas e biogeográficas de uma dada região e essa associação permite que certas classes de sedimentos favoreçam o desenvolvimento de determinadas morfologias de acordo com o ambiente de deposição. Estudos de Casseti (2005) define que a compartimentação topográfica corresponde à individualização de um conjunto de formas com características semelhantes a partir da utilização de uma tipologia específica, que reflita às suas respectivas condições morfogenéticas, morfoclimáticas e litoestratigráficas a que foram submetidas em seu processo 
de formação. A partir da caracterização, identificação e determinação de um padrão de distribuição de sedimentos é possível aventar a criação de uma tipologia de unidades geomorfológicas dotadas de considerável expressão espacial.

De acordo com Martinelli e Pedrotti (2001) as representações cartográficas são um fato social por excelência, sendo um produto do raciocínio humano na busca da realidade concreta. Qualquer paisagem, por mais simples que seja, é sempre social e natural, subjetiva e objetiva, espacial e temporal, produção material e cultural, real e simbólica. Para sua completa apreensão, não basta à análise separada de seus elementos. É preciso compreender sua complexidade, que é dada pela forma, estrutura e funcionalidade. Nesse sentido as observações de Corrêa (2006) dão conta que a criação de uma tipologia de unidades de relevo reflete uma tentativa de organizar as unidades que compõem a paisagem de acordo com a sua consistência processual e dinâmica, e não apenas o estabelecimento de uma classificação geomorfológica da superfície. Para a construção de um sistema de classificação que se adeque a realidade encontrada em campo, é necessário à consideração acerca de sua gênese, formas espaciais, dados morfométricos, processos de superfície e uso da terra, passíveis de serem classificadas e mapeadas numa determinada escala de análise de acordo com a sua distribuição no espaço.

De acordo com Guerra e Marçal (2010) a geomorfologia apresenta ferramentas capazes de definir, delimitar, dividir e espacializar unidades homogêneas e chegar a uma classificação que consiga agrupar as diferentes formas espaciais em níveis hierárquicos capazes de serem identificados em diferentes escalas e, posteriormente, representados através de mapas ou cartas topográficas. O mapeamento geomorfológico apresenta, através de metodologias apropriadas, a configuração da superfície terrestre e ressalta com destaque que as unidades de relevo podem ser utilizadas como base para outras classes de mapas, podendo se constituir em um importante instrumento de análise ambiental capaz de fornecer uma série de informações que irão subsidiar propostas de planejamento, tendo em vista que o conhecimento ordenado da paisagem pode auxiliar um o uso da terra mais consciente.

As pesquisas de Dominguez (1990); Lima Filho et. al. (1991); Costa et. al. (1994); CPRM (1994); Vasconcelos e Bezerra (2000); CPRM (2001); Gusmão Filho (2002) e Corrêa (2006) constituíram o referencial teórico para a atual pesquisa. Ao fazer essas leituras é possível encontrar uma série de sistemas de classificação baseados em diversos critérios, demonstrando a relevância da compartimentação do ambiente de planície em subunidades capazes de refletir com clareza a estrutura superficial da paisagem e a dinâmica superficial de 
cada um dos setores da planície do Recife. A compartimentação da paisagem em unidades e subunidades de paisagem em planícies costeiras tem sido realizada de forma corrente e possui uma vasta literatura nas mais variadas regiões brasileiras, nesse sentido merecem destaque os estudos de caso propostos por Meireles (2002); França et. al. (2006); Cardoso et. al. (2009) e Waldburguer e Gomes (2016).

\section{Área de Estudo}

A planície do Recife localiza-se no litoral oriental do Nordeste do Brasil, na porção central do estado de Pernambuco. Limita-se com as cidades de Olinda, Camaragibe, São Lourenço da Mata e Jaboatão dos Guararapes, ocupando mais da metade da extensão territorial do Recife, e em alguns setores chega a ultrapassar os limites territoriais e adentrar alguns dos municípios citados anteriormente (figura 01).

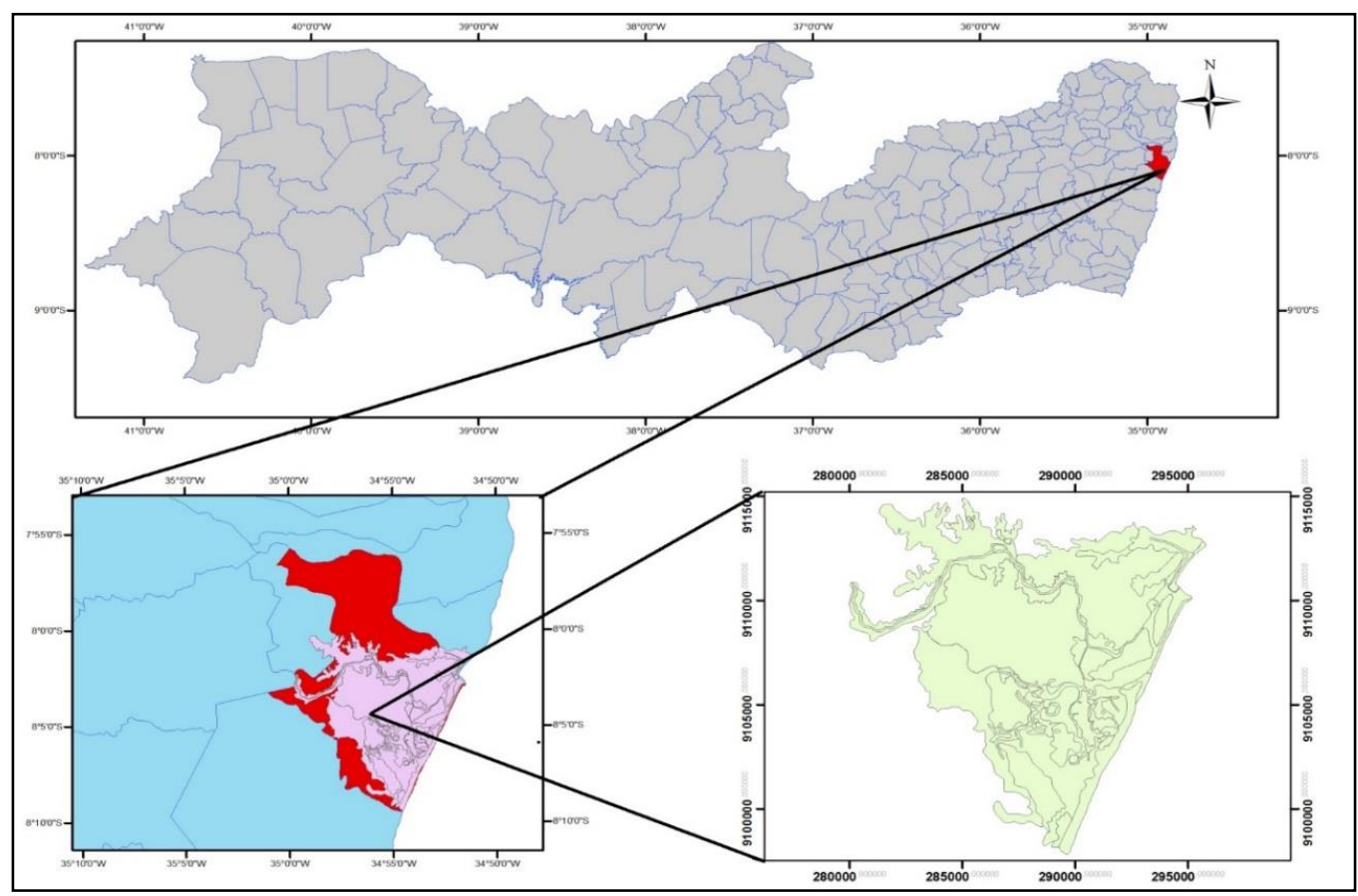

Figura 01. Localização da planície do Recife. Elaboração própria a partir dos dados do Zoneamento Agroecológico de Pernambuco (Embrapa Solos Recife). Projeção Transversa de Mercator, DATUM: WGS 1984 - FUSO 25S.

Evidências propostas por Costa et. al. (1994) apontam que durante o quaternário foram depositados uma grande variedade de sedimentos com características sedimentológicas bastante heterogêneas, evidenciando a coexistência de diferentes processos de deposição ao longo de várias escalas temporais, sobre os depósitos do cretáceo e neógeno na área correspondente às bacias Pernambuco/Paraíba, dando origem a uma série de planícies 
costeiras no Nordeste do Brasil. Estudos de Dominguez (1990) comprovam que as sucessivas transgressões e regressões marinhas decorrentes de episódios glaciais e interglaciais ocorridos durante o quaternário são responsáveis pelo modelado recente da planície do Recife. De acordo com Moura (2003) essas variações ambientais foram responsáveis pela ocorrência de diferentes ambientes de sedimentação associados a determinados sistemas deposicionais, gerando, assim, os depósitos correlativos a cada um desses eventos, passíveis de serem observados na configuração atual do atual ambiente de planície.

De acordo com a classificação proposta pela CPRM (2001) os principais tipos de sedimentos encontrados no ambiente superficial da planície do Recife são: Terraços Holocênicos (Qth), Terraços pleistocênicos (Qtp), Quaternário indiferenciado (Qi), Areias aluviais (Qal), Sedimentos fluviolagunares (Qdfl), Sedimentos de mangue (Qm) e Recifes de arenito (Qr), distribuídos espacialmente de acordo com o mapa da figura 02.

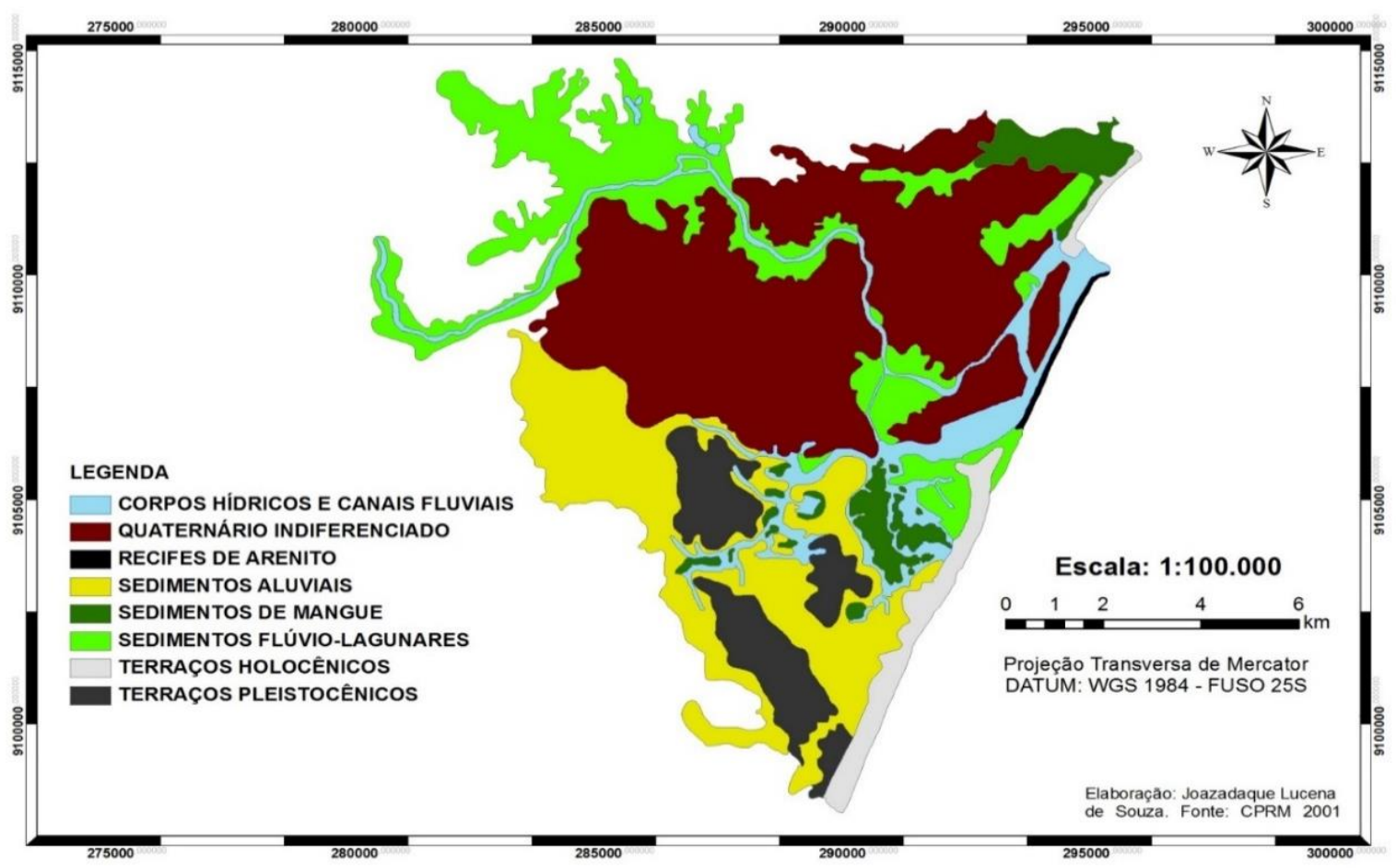

Figura 02. Depósitos quaternários da planície do Recife. Elaboração própria com o uso do ArcGis 9.3. Fonte: (CPRM 2001).

A planície do Recife é parte integrante das bacias sedimentares costeiras Pernambuco e Paraíba, situando-se parcialmente em cada uma delas e fazendo parte de um contexto regional de relevo bastante heterogêneo. Encontra-se limitada ao norte pelas colinas e morros da Formação barreiras, Planície fluviolagunar do rio Beberibe e alguns afloramentos da Formação gramame; a oeste pelo Planalto litorâneo rebaixado e alguns afloramentos da Souza et al., 2017 ISSN 0104-5490 153 
Formação barreiras; ao sul pelos Sedimentos aluviais, Formação barreiras, Formação cabo, além dos compartimentos pertencentes ao Sistema fluviolagunar da lagoa Olho d'água (Planície fluviolagunar, Terraços holocênicos e Terraços pleistocênicos), que se diferencia da planície do Recife em função de um desnivelamento tectônico; e ao leste pelo oceano Atlântico (figura 03).

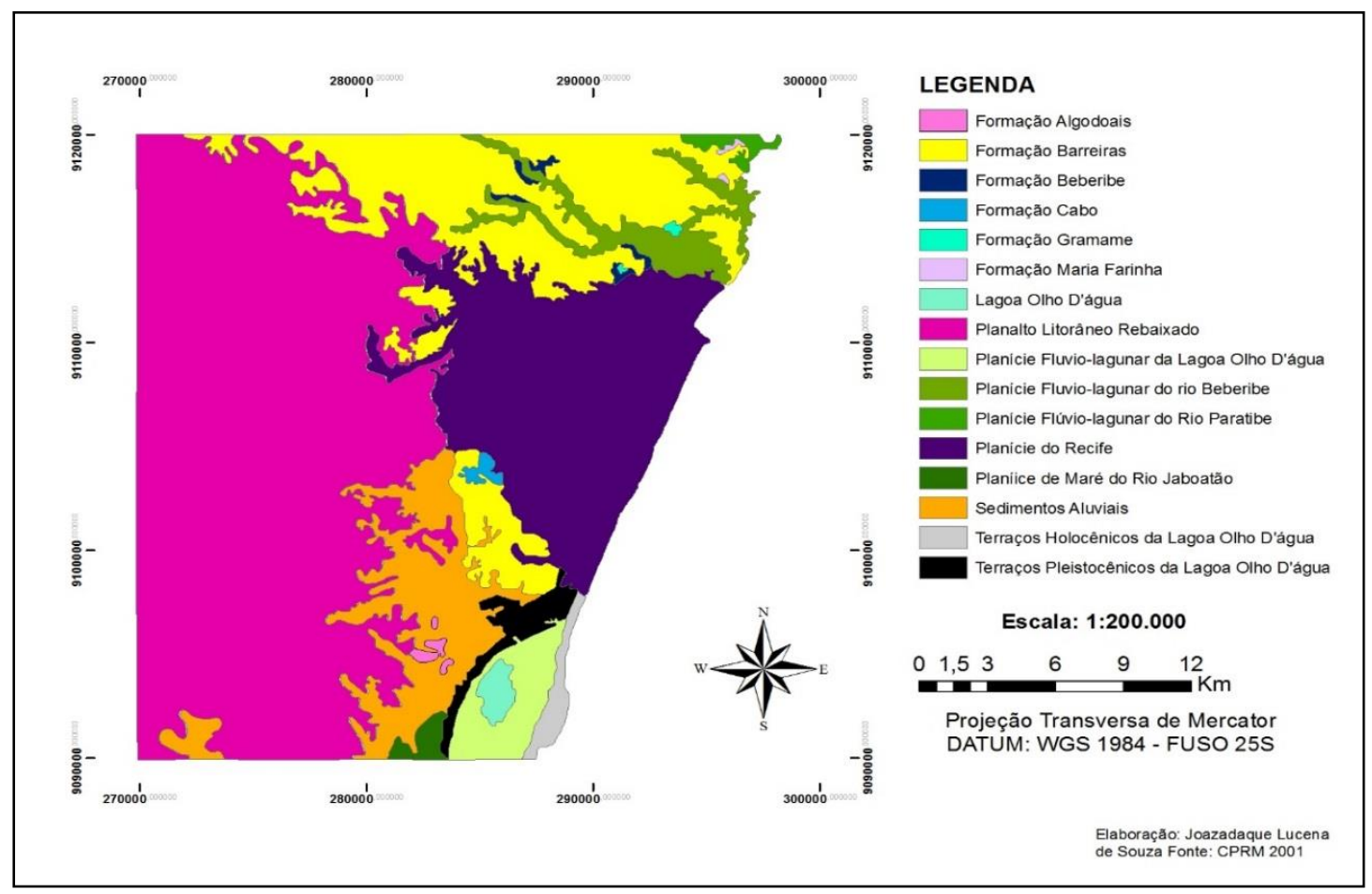

Figura 03. Compartimentação regional de relevo da planície do Recife. Elaboração própria com o uso do ArcGis 9.3. Fonte: (CPRM 2001).

Souza (2013) discorre que os setores situados nas proximidades da zona costeira e cursos fluviais de maior volume são caracterizados por uma topografia plana a levemente plana, apresentando altitudes entre 2 e 6 metros, em decorrência da atuação de processos marinhos, fluviais e fluviomarinhos. A medida em que ocorre o afastamento das áreas litorâneas e dos cursos fluviais de maior volume verifica-se um aumento progressivo das cotas altimétricas, oferecendo condições para ocorrência de compartimentos de relevo situados num outro patamar topográfico, por conta da predominância de processos fluviais, desenvolvidos no ambiente continental, que contribuem para a mudança da configuração da paisagem. Nas porções mais internas da planície situadas nos setores norte e oeste se dá outra quebra de patamar topográfico, causada pela ocorrência de morfologias associadas a uma zona de transição de uma área típica de planície para um ambiente de morros e colinas desenvolvidas sobre terrenos sedimentares formados durante a transição plioceno/pleistoceno. 
Observações de Souza (2013) dão conta que durante o quaternário a referida planície experimentou drásticas modificações em seu ambiente, passando a ser modelada por eventos de naturezas distintas proporcionados pela coexistência de diferentes fluxos de energia e matéria ocorridos durante os momentos de subida generalizada do nível médio dos oceanos em associação à eventos de derretimento das calotas polares. Em contrapartida o ambiente experimentou condições totalmente opostas durante os períodos que houve diminuição do nível médio do mar, condicionados por momentos e grande concentração de gelo nos polos. Esse ambiente também sofreu consideráveis modificações ao longo de períodos de tempo relativamente curtos, quando comparados com a duração dos fenômenos citados anteriormente. No decorrer dos últimos quatro séculos a mesma vem sendo palco de uma série de modificações em suas características iniciais em decorrência da ação antrópica. $\mathrm{O}$ processo de expansão urbana contribuiu de maneira decisiva para a destruição de uma porcentagem considerável dos elementos naturais, alterações na estrutura superficial da paisagem e modificações dos processos de superfície, culminando na quase que total artificialização dos espaços.

\section{Metodologia e Procedimentos metodológicos}

A compartimentação Geomorfológica da planície do Recife está estruturada num sistema de classificação composto de suas escalas hierárquicas que se baseia em aspectos geológicos e geomorfológicos relativos a gênese, cronologia, morfologia e processos de superfície. A elaboração da tipologia de Unidades Geoambientais foi realizada a partir da análise dos ambientes de sedimentação nos diversos setores da planície, das diversas morfologias encontradas na superfície e da vigência de determinados processos superficiais existentes ao longo da paisagem. Para a confecção do segundo nível tipológico de classificação representado pelas Unidades de Relevo foi considerado uma análise mais detalhada da gênese, cronologia e distribuição dos depósitos sedimentares, dados geológicos, geomorfológicos e morfométricos das formas de relevo e geração de risco geomorfológico associados à alterações nos processos de superfície naturais promovidos pela ação antrópica e da geração de risco geomorfológico associados a alterações promovidas pela ação antrópica dotados de considerável expressão espacial.

Inicialmente foi realizada a identificação dos depósitos quaternários a partir da análise do mapa geológico da Região Metropolitana do Recife e a distribuição dos depósitos quaternários disponíveis em CPRM (2001), além da fundamentação teórica presentes nas 
pesquisas de Costa et. al. (1994), CPRM (1994) e Gusmão Filho (2002) para o entendimento do funcionamento dos ambientes de sedimentação e a vigência dos sistemas deposicionais em cada um dos seus diferentes setores foi fundamental para a o entendimento da influência dos controles geológicos de subsuperfície na definição das morfologias existentes na área de estudo.

Em seguida ocorreu a análise da configuração da estrutura superficial da paisagem e dinâmica dos processos de superfície e a verificação das modalidades de risco geomorfológico associado às diversas intervenções e impactos gerados pela ação antrópica ao longo da paisagem foi estabelecida em função dos estudos de Vasconcelos e Bezerra (2000), Carvalho (2004), Corrêa (2006) e Souza (2013). É pertinente salientar que os tipos de risco geomorfológico encontrados em cada um dos setores da planície estão relacionados com a distribuição dos depósitos sedimentares e associados diretamente com as formas de relevo encontradas na paisagem.

Posteriormente foi utilizado o software ArcGis 9.3 (Licença do Laboratório de Geomorfologia do Departamento de Geografia da Universidade Federal de Pernambuco) como ferramenta para a confecção de mapas temáticos capazes de representar espacialmente numa escala de 1:100.000 a distribuição dos depósitos quaternários da planície do Recife, o contexto regional de relevo, e principalmente, os dois níveis hierárquicos da compartimentação de geomorfológica da planície do Recife.

\section{RESULTADOS E DISCUSSÕES}

A tipologia de unidades de relevo proposta por esse estudo permitiu a compartimentação da planície do Recife em dois níveis distintos. O primeiro se refere a uma repartição do espaço baseado em Unidades Geoambientais, que consideram a predominância de determinado ambiente de deposição e a associação de determinados sistemas deposicionais atuantes em seus diferentes setores. O segundo está baseado numa escala hierárquica que possui maior riqueza de detalhes, as Unidades de Relevo, estando relacionado com a distribuição das morfologias encontradas na área de estudo (tabela 01).

As Unidades Geoambientais foram estabelecidas a partir da distribuição dos ambientes de sedimentação e sistemas deposicionais apreendidos em escala regional, sendo divididas em: Planície marinha, Planície fluviomarinha, Planície fluvial, Planície indiferenciada e Corpos hídricos e canais fluviais (figura 04). 
Revista de Geografia (Recife) V. 34, No. 1, 2017

\begin{tabular}{l|l|l}
\hline \multicolumn{2}{c}{ TIPOLOGIA DE RELEVO DA PLANíCIE DO RECIFE } \\
\hline \multirow{3}{*}{ Planície do Recife } & Unidade Geoambiental & \multicolumn{1}{c}{ Unidade de Relevo } \\
\cline { 2 - 3 } & Planície marinha & Terraço marinho holocênico \\
\cline { 2 - 3 } & Planície marinha & Terraço marinho pleistocênico \\
\cline { 2 - 3 } & Planície fluvial & Terraço fluviomarinho holocênico \\
\cline { 2 - 3 } & \multirow{2}{*}{ Planície indiferenciada } & Planície de restinga \\
\cline { 2 - 3 } & $\begin{array}{l}\text { Planície de maré } \\
\text { indiferenciada }\end{array}$ \\
\cline { 2 - 3 } & $\begin{array}{l}\text { Corpos hídricos e canais } \\
\text { fluviais }\end{array}$ & Corpos hídricos e canais Fluviais \\
\cline { 2 - 3 } & Plaviolagunar \\
\hline
\end{tabular}

Tabela 01. Tipologia de Relevo da planície do Recife. Fonte: Souza (2013).

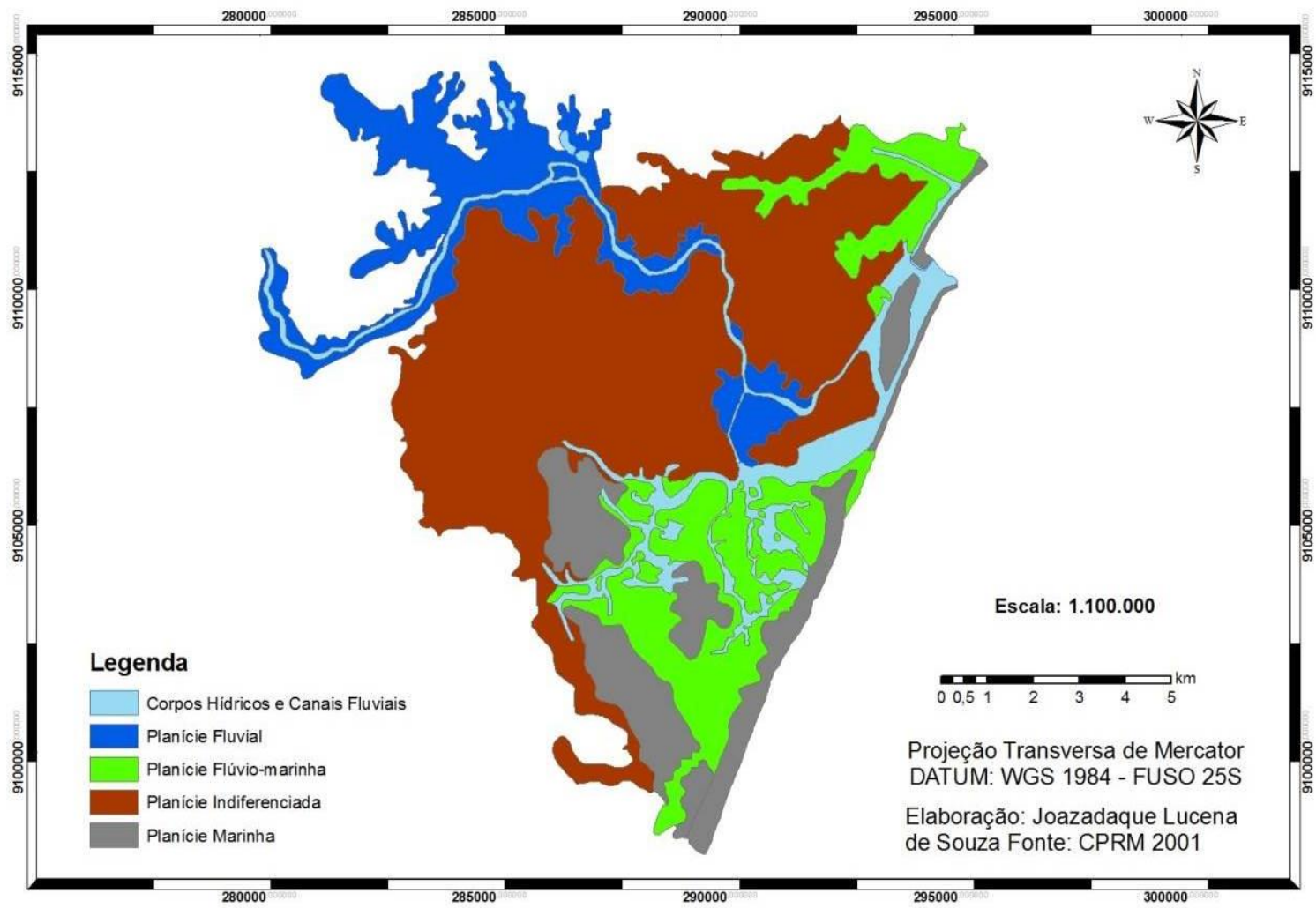

Figura 04. Unidades Geoambientais da planície do Recife. Elaboração própria com o uso do software ArcGis 9.3. Fonte: (CPRM 2001). 
Planície marinha - Encontra-se situada ao longo da atual faixa litorânea do município do Recife, correspondentes à zona sul e centro da cidade, e antigas linhas de praia situadas na porção sudoeste da planície, formadas em momentos pretéritos durante a vigência de um nível médio do mar mais elevado que o atual. Abrange as unidades de relevo classificadas como Terraço marinho holocênico e Terraço marinho pleistocênico. Esse ambiente ocorre na paisagem em função da propagação da energia das ondas ao longo do litoral, consistindo no principal fator responsável pela erosão, transporte e acumulação de sedimentos ao longo do prisma praial, onde vigoram os processos típicos do ambiente de deposição costeiro.

Planície fluviomarinha - Situa-se na interface entre os ambientes costeiro e fluvial, nas áreas estuarinas dos principais rios que executam a drenagem do Recife e compartilham um estuário comum nas bacias Portuária e Pina. É formado pelas zonas de alcance das marés, localizadas no setor sul da planície, influenciadas pela ação dos rios Tejipió, Pina, Jordão e Jiquiá, além do setor norte, associadas aos cursos fluviais do Capibaribe e Beberibe. É abrange o Terraço fluviomarinho holocênico, Planície de maré e Planície de restinga, unidades de relevo que sofrem a ação de processos fluviais e marinhos.

Planície Fluvial - É representada pelos setores da planície abrangidos pela dinâmica fluvial, formados pelos processos relacionados à erosão, transporte e deposição de sedimentos em ambientes aluvionares. A deposição de sedimentos, típicas dos sistemas fluviais, é responsável pela formação das áreas planas ou em forma de terraço, adjacentes aos cursos fluviais, formando as áreas de planície próximas aos canais fluviais, através dos processos de anexação de barras fluviais, migração de meandros e preenchimento de antigas planícies de inundação. É representada pela unidade de relevo intitulada de Planície fluviolagunar e tem uma contribuição muito grande na formação dos terraços indiferenciados.

Planície Indiferenciada - Ocorre na paisagem em função da interação de uma série de ambientes de deposição e sistemas deposicionais que atuam, de forma complexa, conjuntamente ou não, em um mosaico de relações dinâmicas que envolvem uma série de fluxos de energia e matéria, ao longo de uma mesma porção do espaço, gerando diversas características sedimentológicas, estratigráficas e morfológicas. As duas áreas de maior destaque são: a zona de contato entre o ambiente de planície e as encostas da Formação barreiras sob a forma de leques aluviais zona de contato entre o ambiente de planície e a área de morros e colinas circundam a porção sudoeste da referida planície; e ao longo de seu setor norte, em decorrência da intercalação complexa de sedimentos fluviais e fluviomarinhos, 
gerados por sucessivas transgressões e regressões, responsáveis pela alternância de sucessões de famílias de formas geomórficas nas áreas de várzea associadas ao rio Capibaribe.

Corpos Hídricos e Canais Fluviais - Essa unidade de relevo encontra-se situada ao longo dos ambientes de Sedimentação lacustre e fluvial, respectivamente. É composta por uma malha de corpos hídricos responsáveis pela drenagem do Recife. Compõem o ambiente de deposição fluvial, sendo responsáveis pelos fluxos hídricos canalizados e recebem os sedimentos provenientes do fluxo difuso realizado nos ambientes de maior gradiente topográfico, sendo fundamentais para o transporte de sedimentos no leito dos canais fluviais, em suspensão ou em solução iônica, dependendo do tipo e tamanho da partícula a ser transportada, executando um trabalho significativo na construção das áreas planas da cidade. São responsáveis pela drenagem de água e sedimentos sobre a forma de fluxos canalizados das diversas bacias hidrográficas dos rios Capibaribe, Beberibe, Tejipió, Pina, Jordão, Jiquiá e Curado. Todos os cursos fluviais têm foz conjunta no contato com o oceano Atlântico ao longo do sistema estuarino pertencente à bacia do Pina.

O segundo nível hierárquico de compartimentação é representado pelas Unidades de Relevo. Representam subdivisões das Unidades Geoambientais, mas com dinâmica processual própria adequada a escala de análise específicas a um tratamento relativo a estrutura superficial da paisagem e dinâmica dos processos de superfície, mas que ao mesmo tempo resguardam as características morfológicas e dinâmica processual vigentes na escala hierárquica superior, sendo parte integrante das mesmas. As unidades de Relevo (figura 05) são representadas pelo Terraço marinho holocênico, Terraço marinho pleistocênico, Terraço fluviomarinho holocênico, Terraço indiferenciado, Planície de maré, Planície fluviolagunar, Planície de restinga, Planície colúvio-aluvial indiferenciada, e Corpos hídricos e canais fluviais. A partir dessa escala de análise torna-se mais evidente a interferência da ação antrópica sobre as morfologias e processos de superfície, tornando-se possível estabelecer relações entre as modificações antrópicas e a mudanças na dinâmica natural vigente em cada uma das unidades de relevo. 


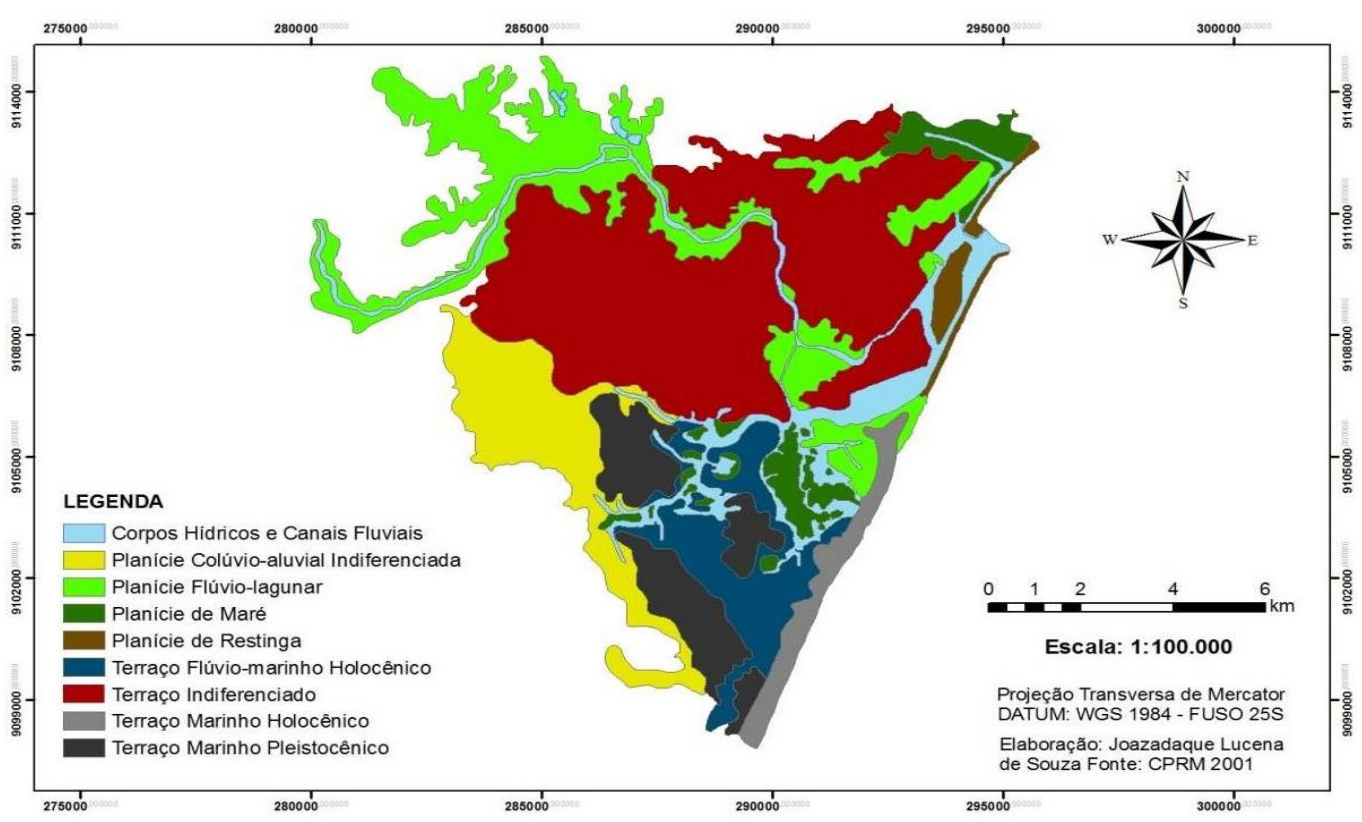

Figura 05. Unidades de Relevo da planície do Recife. Elaboração própria com o uso do software ArcGis 9.3. Fonte: (CPRM, 2001)

Terraco marinho holocênico - É composto pelos sedimentos Qth, formados a partir de uma regressão marinha ocorrida há cerca de 5.100 anos A.P. Está situado na porção litorânea da planície sob a forma de cordões litorâneos alongados, contínuos e paralelos ao oceano. Com uma área de $4 \mathrm{~km}^{2}$, largura média de $1 \mathrm{~km}$ e altitudes entre 2 a $4 \mathrm{~m}$, são representados pela atual linha de costa, que se estende entre os bairros de Boa Viagem e Pina, na zona sul do Recife. É submetido frequentemente à erosão marinha e o retrabalhamento de sedimentos pelas ondas, marés e correntes, é perceptível a ocorrência de erosão do prisma praial como resultado do avanço da urbanização em direção ao litoral, gerando recuo da linha de costa.

Terraço marinho pleistocênico - É constituído pelos sedimentos Qtp, depositados por uma regressão marinha há cerca de 120.000 anos A.P. Localiza-se em uma porção mais interna da planície sob a forma de antigas cristas praiais com cotas altimétricas variando entre 6 e $12 \mathrm{~m} \mathrm{e}$ uma área de pouco mais de $10 \mathrm{~km}^{2}$. Apresentam-se como antigas linhas praiais vigentes em momentos pretéritos, quando o nível médio do mar estava mais elevado que o atual, na zona sudoeste do município de Recife, numa posição paralela à atual aos Terraços marinhos holocênicos, na área correspondente aos bairros de Boa viagem, Imbiribeira, Caçote, Areias, Estância, Jiquiá, Jardim São Paulo e Barro, nas imediações do Aeroporto Internacional dos Guararapes. É percebida a impermeabilização do solo com concreto, asfalto e pavimento, impedindo a infiltração de água e favorecendo o escoamento superficial, gerando uma série de alagamentos em dias chuvosos. 
Terraco fluviomarinho holocênico - Possui composição predominante das areias aluviais (Qal), formados através do retrabalhamento fluvial dos sedimentos dos terraços holocênicos (Qth) e pleistocênicos (Qtp) após o rebaixamento do nível do mar ocorrido, há cerca de 5.100 anos A.P. Encontra-se distribuído na paisagem sob a forma de terraços alongados encaixados entre os Terraços marinhos holocênicos e pleistocênicos, que foram intensamente dissecados pela ação fluvial. Apresentam depósitos com alto nível de heterogeneidade e se confundem por vezes com os Terraços marinhos holocênicos, Planície aluvial e Planície de maré, formando um mosaico que reflete a ocorrência de zonas de contato e transição com as referidas unidades. Situam-se na zona sudoeste da planície do Recife, na área que correspondente aos bairros de Boa Viagem, Imbiribeira, Ipsep, Ibura, Caçote, Areias, Estância e Jiquiá, ocupando uma área de 9,6 km². É possível verificar a ocorrência de enchentes durante episódios chuvosos e/ou de subida generalizada das marés nas áreas mais próximas ao corpos hídricos e alagamentos, resultantes da dificuldade de escoamento superficial em dias chuvosos nas áreas mais afastadas dessas massas líquidas.

Planície de restinga - É Formada pelos sedimentos Qtp (terraços pleistocênicos), Qth (terraços holocênicos) e Qi (quaternário indiferenciado), sob a forma de um cordão arenoso disposto paralelamente à linha de costa e adjacente a foz dos rios Capibaribe e Beberibe. Apresenta uma área de $1,9 \mathrm{~km}^{2}$ dispostos na região correspondente ao bairro do Recife, na parte central do Recife, uma outra no município de Olinda (situado ao norte do Recife) e uma terceira nos bairros do Pina e Brasília Teimosa, nas imediações da bacia Portuária. O cordão litorâneo funciona como uma barreira ao canal, onde predominam os processos de erosão marinha e fluvial. Uma parcela considerável dos sedimentos que compõem essa unidade de relevo é composta pelos recifes de arenito (Qr), que representam antigos níveis praiais, paralelos a costa, protegendo o continente da erosão costeira. As alterações promovidas pela ação antrópica promoveram o corte da restinga e a transformação do istmo em ilha, a anexação de barras fluviais através de grandes volumes aterros para o aumento da área construída.

Planície de maré - Constitui regiões planas situadas na zona de contato entre os baixos cursos fluviais das áreas que sofrem influência da maré que compõem os manguezais, que e que se adapta a um substrato formado pelos sedimentos de mangue $(\mathrm{Qm})$ e à variação de volume e salinidade da água. Com uma área de $5 \mathrm{~km}^{2}$, localiza-se no estuário comum na área compreendida pela bacia Pina, ao sul da planície, nos bairros do Pina, Imbiribeira, Areias, 
Jiquiá, Afogados e Ibura e associada aos baixos cursos fluviais dos rios Beberibe e Capibaribe, situados nos bairros correspondentes ao setor norte do ambiente de planície, como Santo Amaro, Campo Grande, Peixinhos, Boa Vista e Recife Antigo, e setores correspondentes a cidade de Olinda. É verificada a ação de marés, erosão e sedimentação fluvial. Apresenta episódios de enchentes decorrentes do desmatamento no entorno dos corpos hídricos, aterros, impermeabilização do solo e construções irregulares.

Planície fluviolagunar - Constitui áreas baixas sujeitas a inundações periódicas, compostas pelos sedimentos Fluviolagunares (Qdfl), resultantes da deposição fluvial. Localiza-se nas proximidades dos corpos hídricos de considerável dimensão e principalmente nos cursos dos rios Capibaribe e Beberibe, se estendendo como uma franja ao longo dos seus cursos em direção ao interior da planície. Ocupa uma área de $23,4 \mathrm{~km}^{2}$, abrangendo os bairros das áreas: central do Recife (Boa Vista, Joana Bezerra, São José, Afogados, Paissandu, Ilha do Leite, Santo Amaro, Derby e Ilha do Retiro); sul (Pina e Brasília Teimosa); oeste (Torre, Madalena, Zumbi, Cordeiro, Iputinga, Várzea, Caxangá) e norte (Arruda, Tamarineira, Ponto de Parada, Jaqueira, Parnamirim, Poço, Santana, Monteiro, Apipucos e Dois irmãos). Há um predomínio dos processos de erosão e acumulação de sedimentos nas áreas adjacentes ao canal fluvial. Também é verificada a ocupação da várzea dos rios por áreas agrícolas, comunidades carentes, edifícios e condomínios de luxo, constituindo uma área de grande densidade populacional.

Planície colúvio-aluvial indiferenciada - É representada pelas areias aluviais (Qal), depositados ao longo dos baixos cursos fluviais dos rios Tejipió, Jordão, Jiquiá e Curado, preenchendo-os de sedimentos durante os períodos de cheia. Margeiam os Terraços Marinhos pleistocênicos, a Formação barreiras, Formação cabo e o Planalto litorâneo rebaixado, de litologia cristalina, situando-se na zona oeste da cidade, numa área correspondente aos bairros da Várzea, Curado, Coqueiral, Sancho, Tejipió, Barro, Jardim São Paulo, Ibura, Jordão, Imbiribeira, Estância e Jiquiá, perfazendo uma área de $12,9 \mathrm{~km}^{2}$. Apresenta uma topografia plana à levemente inclinada, decorrente do entalhe fluvial dos sedimentos dos morros e colinas da formação barreiras que circundam o ambiente de planície. Apresenta cotas altimétricas variáveis, com tendência de diminuição da altitude das áreas de encosta em direção ao ambiente de planície, o que reflete a ação do ambiente de leques aluviais. É intensamente ocupada por áreas residenciais de baixa renda, a vegetação foi quase que totalmente retirada, alterando a dinâmica do escoamento superficial e contribuindo com a 
ocorrência de movimentos de massa nas áreas com maior declividade durante o período chuvoso.

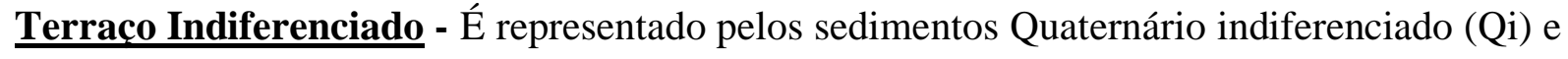
originado a partir e descaracterização dos terraços fluviais do rio Capibaribe e sua respectiva anexação aos terraços marinhos (Qth e Qtp) durante as duas últimas transgressões marinhas ocorridas a 10.000 e 5.100 anos A.P., respectivamente e apresentando grande variação sedimentológica, estratigráfica e morfológica (Lima Filho et. al., 1991). São feições contínuas situadas nas adjacências do curso atual e antigas planícies de inundação do rio Capibaribe, na porção norte da planície, em um patamar mais elevado em relação à Planície fluviolagunar associadas às áreas mais próximas ao canal fluvial. Estende-se por diversos setores da metrópole recifense: centro da cidade (Cabanga, São José, Santo Antônio, Boa Vista, Paissandu, Ilha do Retiro, Soledade e Santo Amaro); norte (Campo Grande, Campina do Barreto, Fundão, Espinheiro, Graças, Jaqueira, Encruzilhada, Hipódromo, Torreão, Rosarinho, Tamarineira, Bomba do Hemetério, Mangabeira, Água Fria, Casa Amarela, Casa Forte, Poço, Santana e Monteiro); e oeste (Afogados, Mustardinha, Mangueira, San Martim, Jardim São Paulo, Curado, Jiquiá, Bongi, Torrões, Prado, Madalena, Torre, Zumbi, Cordeiro, Iputinga, Engenho do Meio, Cidade Universitária, Caxangá e Várzea) que somados chegam a $47,6 \mathrm{~km}^{2}$, constituindo a unidade de relevo com maior área na planície do Recife. A urbanização intensa, grandes áreas de aterros e a impermeabilização do solo dificultam o sistema de drenagem e contribuem para a ocorrência de enchentes nas proximidades dos canais fluviais e geração de pontos de alagamentos nas áreas mais afastadas dos mesmos.

Corpos Hídricos e Canais Fluviais - Esta unidade é representada pelos rios, canais fluviais e os demais corpos hídricos (açudes, lagoas, riachos e córregos) presentes na planície do Recife, que somados ocupam uma área de $13,2 \mathrm{~km}^{2}$. São constituídos pela bacia do Pina, situada entre o ambiente de planície e o oceano Atlântico; os cursos fluviais que drenam os setores sul e sudoeste da planície do Recife, representados pelos rios Tejipió, Jordão, Pina, Setúbal, Jiquiá, e Curado; a lagoa do Araçá e demais corpos d'água situados na porção sudoeste do Recife; o rio Beberibe, responsável pela drenagem da zona norte do Recife e o Capibaribe, principal curso fluvial da cidade, responsável pela drenagem da porção central, zona norte e oeste, que também apresenta um conjunto de açudes situados nos bairros de Apipucos e Dois Irmãos. Verifica-se a ocorrência do escoamento superficial difuso de água e sedimentos a partir de fluxos canalizados. As obras de canalização, retificação e supressão dos corpos hídricos provocam oscilação nas taxas de erosão e sedimentação em suas margens decorrentes da 
destruição da mata ciliar e poluição hídrica por esgoto e resíduos sólidos, gerando assoreamento e transbordamento dos cursos fluviais.

De acordo com as definições de Ross (2003) as intervenções promovidas pela ação antrópica na paisagem deveriam ser precedidas por um minucioso entendimento dos processos e leis que regem seu funcionamento, e a elaboração de diagnósticos ambientais adequados. $\mathrm{O}$ entendimento da dinâmica das diversas hierarquias de unidades de paisagem, onde as formas do relevo se inserem como um dos componentes de grande importância, é indispensável para a modelagem dos sistemas ambientais. Interpretar o relevo não se resume a saber identificar padrões de formas ou tipos de vertentes e vales, descrever o comportamento geométrico das formas, mas saber identificá-las e correlacioná-las com os processos presentes e pretéritos responsáveis por tais modelados, assim como descrito na tabela 02. Dentro dessa perspectiva os estudos relativos ao entendimento da estrutura superficial da paisagem e os processos de superfície vigentes numa área intensamente urbanizada podem auxiliar no planejamento do uso da terra e contribuir com uma melhor gestão do espaço geográfico.

\begin{tabular}{|c|c|c|}
\hline \multicolumn{3}{|c|}{$\begin{array}{l}\text { MORFOLOGIA E PROCESSOS DE SUPERFÍCIE DAS UNIDADES DE RELEVO DA } \\
\text { PLANÍCIE DO RECIFE }\end{array}$} \\
\hline $\begin{array}{l}\text { UNIDADE DE } \\
\text { RELEVO }\end{array}$ & MORFOL & $\overline{\text { SUPEI }}$ \\
\hline $\begin{array}{l}\text { Terraço Marinho } \\
\text { Holocênico }\end{array}$ & \begin{tabular}{|l|l|} 
Cordões litorâneos alongados \\
paralelos à linha de costa.
\end{tabular} & $\begin{array}{l}\text { Ação das marés, ondas, correntes, erosão } \\
\text { marinha decorrente de construções } \\
\text { irregulares. }\end{array}$ \\
\hline $\begin{array}{l}\text { Terraço Marinho } \\
\text { Pleistocênico }\end{array}$ & $\begin{array}{l}\text { Cordões arenosos no interior da } \\
\text { planície. }\end{array}$ & $\begin{array}{l}\text { Escoamento superficial fora do alcance das } \\
\text { marés, impermeabilização do solo e geração } \\
\text { de alagamentos. }\end{array}$ \\
\hline $\begin{array}{l}\text { Terraço } \\
\text { Fluviomarinho } \\
\text { Holocênico }\end{array}$ & $\begin{array}{l}\text { Faixa areno-argilosa encaixado entre } \\
\text { os Terraços Marinhos Holocênico e } \\
\text { Pleistocênico. }\end{array}$ & $\begin{array}{l}\text { Escoamento superficial difuso e Intenso } \\
\text { retrabalhamento fluvial, ocorrência de } \\
\text { enchentes e alagamentos. }\end{array}$ \\
\hline $\begin{array}{l}\text { Planície } \\
\text { Restinga }\end{array}$ & $\begin{array}{l}\text { Cordão arenoso no contato com o } \\
\text { oceano e modelado por processos } \\
\text { fluviais. }\end{array}$ & $\begin{array}{l}\text { Erosão marinha e fluvial e alongamento do } \\
\text { cordão arenoso, ocorrência de aterros e } \\
\text { alterações na morfologia dos cordões } \\
\text { arenosos. }\end{array}$ \\
\hline Planície de Maré & $\begin{array}{l}\text { Áreas planas situadas ao longo dos } \\
\text { baixos cursos fluviais sob a forma de } \\
\text { manguezais. }\end{array}$ & $\begin{array}{l}\text { Ação das marés e deposição fluviomarinha. } \\
\text { Desmatamento das margens e supressão dos } \\
\text { corpos hídricos com áreas de aterro, }\end{array}$ \\
\hline
\end{tabular}




\begin{tabular}{|c|c|c|}
\hline & & $\begin{array}{l}\text { impermeabilização do solo e construções } \\
\text { irregulares. }\end{array}$ \\
\hline $\begin{array}{l}\text { Planície } \\
\text { Fluviolagunar }\end{array}$ & $\begin{array}{l}\text { Áreas planas margeando os cursos } \\
\text { fluviais até o interior da planície. }\end{array}$ & $\begin{array}{l}\text { Erosão e deposição nas margens dos rios, } \\
\text { ocupação por áreas residenciais e agrícolas. }\end{array}$ \\
\hline $\begin{array}{l}\text { Planície Colúvio- } \\
\text { aluvial } \\
\text { indiferenciada }\end{array}$ & $\begin{array}{l}\text { Áreas planas a levemente inclinadas } \\
\text { no contato com as colinas da } \\
\text { formação barreiras. }\end{array}$ & $\begin{array}{l}\text { Erosão no alto curso e deposição no baixo } \\
\text { curso dos rios, movimentos de massa nas } \\
\text { áreas com maior declividade }\end{array}$ \\
\hline $\begin{array}{l}\text { Terraço } \\
\text { Indiferenciado }\end{array}$ & $\begin{array}{l}\text { Grande variação morfológica ao longo } \\
\text { dos setores da planície. }\end{array}$ & $\begin{array}{l}\text { Escoamento difuso fora do alcance das marés, } \\
\text { urbanização } \\
\text { impermeabilização do solo e geração de } \\
\text { alagamentos. }\end{array}$ \\
\hline $\begin{array}{l}\text { Corpos Hídricos } \\
\text { Canais Fluviais }\end{array}$ & $\begin{array}{l}\text { Canais fluviais, Lagoas, açudes e } \\
\text { Estuário das bacias hidrográficas das } \\
\text { Principais bacias hidrográficas que } \\
\text { drenam a planície. }\end{array}$ & $\begin{array}{l}\text { Escoamento de água e sedimentos a partir de } \\
\text { fluxos canalizados. Canalização, retificação e } \\
\text { supressão dos corpos hídricos e destruição da } \\
\text { mata ciliar de suas margens e poluição } \\
\text { hídrica. }\end{array}$ \\
\hline
\end{tabular}

Tabela 02. Morfologia e processos de superfície da planície do Recife. Fonte: (Souza 2013)

\section{CONCLUSÕES}

O presente trabalho produziu um modelo de compartimentação da planície do Recife em unidades de paisagem pautado em uma tipologia com dois níveis hierárquicos com o objetivo de entender a complexidade dos ambientes existentes ao longo de seus diferentes setores, a partir da análise das características geológicas, geomorfológicas, processos de superfície e alterações promovidas pela ação antrópica. Foi evidenciado que a deposição sedimentar é um fator muito importante na gênese e evolução das formas de relevo, evidenciando a relação entre os ambientes subsuperfície e superfície. Os Terraços marinhos holocênico e pleistocênicos apresentam um modelo de deposição sedimentar comandado pelo ambiente de sedimentação costeira; o Terraço fluviomarinho holocênico, Planície de maré e planície de restinga apresentam uma arquitetura deposicional correspondente ao ambiente estuarino; a Planície fluviolagunar e parte considerável da área do Terraço indiferenciado são possuem uma deposição típica do ambiente fluvial; os corpos hídricos e canais fluviais constituem morfologias formadas pelo ambiente fluvial e lagunar; a Planície colúvio-aluvial Indiferenciada é representada pelo ambiente de leques aluviais, reforçando a inter-relação existente entre deposição sedimentar, forma de relevo e processos de superfície. 
A tipologia de unidades de relevo sugerida neste estudo tem o intuito de contribuir com o conhecimento da geomorfologia do ambiente de planície do Recife, explicitando o seu processo de formação e evolução ao longo das diferentes escalas espaciais e temporais. Nesse sentido, a compartimentação é apenas o primeiro passo para a criação de um zoneamento ambiental em uma área intensamente urbanizada, sendo necessário analisar, avaliar e mensurar de forma qualitativa e quantitativa os impactos a ação antrópica sobre cada uma das unidades de relevo, tendo em vista que a urbanização tem promovido alterações na morfologia e na dinâmica processual dos sistemas ambientais. Somente a partir de tais pressupostos torna-se possível aventar um modelo de planejamento urbano que dê conta das características físico-ambientais, das respectivas alterações nos processos de superfície e a respectiva geração de risco geomorfológico e, sobretudo, da necessidade de ações que promovam a prevenção e mitigação dos impactos socioambientais que, ainda, persistem na área do Recife, compreendida pelo ambiente de planície.

\section{REFERÊNCIAS BIBLIOGRÁFICAS}

CARDOSO, D.; RIEDEL, P. S.; VEDOVELLO, R.; BROLLO, M. J.; TOMINAGA, L. K. Compartimentação fissiográfica do município de Peruíbe, litoral de São Paulo - uma abordagem metodológica como subsídio a avaliação geotécnica de terrenos. Pesquisas em Geociências (UFRGS. Impresso), v. 36(3), p. 251-262, 2009.

CARVALHO, L.E.P. Os descaminhos das águas no Recife: os canais, os moradores e a gestão. Recife, 2004. 140 folhas Dissertação (mestrado) - Universidade Federal de Pernambuco. CFCH. Geografia.

CASSETI, Valter. Geomorfologia. [S.1.]: [2005]. Disponível em: <http://www.funape.org.br/geomorfologia/> Acesso em: 21/01/2013.

CHRISTOFOLETTI, Antonio. Análise de sistemas em geografia. São Paulo: Hucitec - Ed. Da universidade de São Paulo, 1979. 106p

CHRISTOFOLETTI, Antonio. Geomorfologia. 2 ed. São Paulo: Edgard Blucher, 1980. 88p.

CHRISTOFOLETTI, Antonio. Modelagem de Sistemas Ambientais. São Paulo: Edgar Blücher, 2000. 236p. 
COMPANHIA PESQUISA DE RECURSOS MINERAIS-CPRM, 1994. Sistema de Informações para a gestão territorial da região Metropolitana do Recife - Projeto SINGRE, Vulnerabilidade das águas Subterrâneas da região metropolitana do Recife: CPRM/FIDEM. 27p. (Série Recursos Hídricos, 2).

COMPANHIA PESQUISA DE RECURSOS MINERAIS-CPRM, 2001. Sistema de Informações para a Gestão Territorial da Região Metropolitana do Recife - Projeto SINGRE II, Atividades impactantes sobre o meio ambiente da Região Metropolitana do Recife: 81p. (Série Degradação Ambiental - Volume 02).

CORRÊA, Antonio Carlos de Barros. Contribuição a análise do Recife como um Geossistema Urbano. Revista do Departamento de Geografia DCG/NAPA-UFPE Recife. v.23, nº 3, jul/dez, pag.86-105, 2006.

COSTA, Waldir Duarte; SANTOS, Almany Costa; COSTA FILHO, Waldir Duarte. O controle estrutural na formação dos aquíferos na planície do Recife. In: $8^{\circ}$ Congresso Brasileiro de águas Subterrâneas. Recife, ABAS. pag. 38-43, 1994.

DOMINGUEZ, José Maria Landim; BITTENCOURT, Abílio Carlos Silva; MARTIN, Louis. Esquema evolutivo da sedimentação quaternária nas feições deltaicas dos rios São Francisco (SE/AL), Jequintinhonha (BA), DOCE (ES) e Paraíba do Sul (RJ). Revista Brasileira de Geociências, v.11, p.225-237, 1981.

EVASO, Alexander Sérgio. A refuncionalização do espaço. Experimental. São Paulo: v.3, n.6. p. 33-54, 1999.

FRANÇA, C. F.; SOUZA FILHO, P. W. M. E. . Compartimentação morfológica da margem leste da ilha de Marajó: zona costeira dos municípios de Soure e Salvaterra, Estado do Pará. Revista Brasileira de Geomorfologia, v. 1, p. 33-42, 2006.

GIRÃO, Osvaldo; CORRÊA. Antonio Carlos de Barros. A Contribuição da Geomorfologia para o planejamento da Ocupação de Novas Áreas. Revista do departamento de geografia DCG/NAPA-UFPE. Recife, v.21. nº 2 jul/dez. 2004.

GUERRA, Antonio José Teixeira; MARÇAL, Mônica Santos. Geomorfologia Ambiental. Rio de Janeiro: Bertrand Brasil, $3^{\circ}$ Ed; 2010. 189 p. 
GUSMÃO FILHO, Jaime de Azevedo. Fundações do conhecimento geológico a prática da engenharia. Recife: Ed. Universidade da UFPE, 2002.

LIMA FILHO, M. F.; CORRÊA, A. A.; MABESOONE, J.; SILVA, J. C. Origem da Planície do Recife, in: Estudos Geológicos: revisão geológica da faixa costeira de Pernambuco, Paraíba e parte do Rio Grande do Norte. Recife, 1991. DGEO, SÉRIE B: ESTUDOS E PESQUISAS.

MARTINELLI, Marcello; PEDROTTI, Franco. A cartografia das unidades de paisagem: Questões metodológicas. Revista do departamento de geografia, 14 (2001) 39-46.

MEIRELES, A. J. A.; Serra. Um modelo geomorfológico integrado para a planície costeira de Jericoacoara/Ceará. Mercator, Fortaleza/Ceará, v. 1, p. 79-94, 2002.

MOURA, Josilda Rodrigues da Silva. Geomorfologia do Quaternário. In: GUERRA, Antonio José Teixeira; CUNHA, Sandra Batista. (eds.) Geomorfologia uma atualização de bases e conceitos. Rio de Janeiro: Bertrand Brasil, $5^{\text {a }}$ ed., 2003, p.149-209.

ROSS, Jurandyr Luciano Sanches. Geomorfologia ambiente e planejamento. 7 ed. São Paulo: Contexto, 2003.

SOUZA, Joazadaque Lucena. 2013. Morfodinâmica e processos superficiais das unidades de relevo da planície do Recife. Recife. Dissertação (mestrado) - Universidade Federal de Pernambuco, CFCH. Programa de Pós-graduação em Geografia.

TRICART, Jean. Ecodinâmica. Rio de Janeiro, IBGE, Diretoria técnica, SUPREN, 1977, 91 p.

VASCONCELOS, R. F. A; BEZERRA, O. G. (2000). Atlas Ambiental do Recife. Prefeitura da Cidade do Recife/Secretaria de Planejamento, Urbanismo e Meio Ambiente. Recife - PE, $151 \mathrm{p}$.

WALDBURGUER, T. C. M.; GOMES, R. L. Mapeamento Geoambiental da Zona Costeira dos Municípios de Maraú e Camamu - BA. Revista de Geografia (Recife), v. 33, p. $230-250,2016$. 